\title{
Monitoring Measures in the Elimination of Malaria in Fujian, China: A Cost-Benefit Analysis
}

\section{Chun-Yan HUANG}

Fujian Center for Disease Control and Prevention

Shan-Ying Zhang ( $\nabla$ hxyfzz@163.com)

Fujian Center for Disease Control and Prevention

\section{Zhu-Yun CHEN}

Fujian Center for Disease Control and Prevention

Han-Guo XIE

Fujian Center for Disease Control and Prevention

Rong OUYANG

Fujian Center for Disease Control and Prevention

\section{Research Article}

Keywords: Malaria elimination, Cost-benefit analysis, Monitoring effect, Health economics

Posted Date: November 5th, 2020

DOI: https://doi.org/10.21203/rs.3.rs-101262/v1

License: () (i) This work is licensed under a Creative Commons Attribution 4.0 International License. Read Full License 


\section{Abstract}

Background: Malaria is an insect-borne infectious disease that spreads through bites from infected Anopheles mosquitos. The disease seriously endangers human health and economic development. The study focuses on Fujian Province, China, which entered the final stage of malaria elimination stage in 2005. In order to understand the costs and benefits of malaria monitoring measures during the elimination stage, the health economics of the monitoring measures should be examined.

Methods: Data on the number of cases during the malaria elimination stage (2005-2019) in Fujian Province were collected and sorted. The basic economic data were obtained from the Fujian Statistical Yearbook. Based on the fundamental theories in health economics, a cost-benefit analysis was conducted based on the data. Specifically, the cost of monitoring measures during the malaria elimination stage was calculated by economic cost and compared to the benefits, which were quantified based on economic and social benefits of the monitoring measures.

Results: The total cost of monitoring measures in the malaria elimination stage was estimated at $607,878,783.36$ yuan (USD $87,534,544.80)$. The components of the total cost were: case detection and treatment, which accounted for $66.62 \%$ of costs, health education with $13.31 \%$, epidemic monitoring, $10.05 \%$, supervision and assessment, $5.15 \%$, and training and meetings took $4.87 \%$. The total benefit of the monitoring measures in the malaria elimination stage was valued at about $116,123,417,911.81$ yuan (USD 16,721,772,179.30). Direct economic benefit accounted for $22.61 \%$ of the total, while the social benefit was $77.39 \%$. The cost-benefit analysis of the malaria elimination stage showed that the net benefit of monitoring measures was about $115,515,539,128.45$ yuan (USD 16,634,237,634.50) and the benefit-cost ratio was 191.03. The monitoring cost for residents was 1.08 yuan (USD 0.16) per capita, and the benefit for residents was 206.12 yuan (USD 29.68) per capita.

Conclusions: The monitoring measures conducted in the malaria elimination stage are a highly cost-effective intervention for reducing the negative impact of malaria in Fujian Province. Over the past 15 years, malaria control work has achieved excellent economic and social benefits in Fujian and the work should continue. The framework and results of this study conform to the principles of health economics and have a reference value for current malaria monitoring practices.

\section{Background}

Malaria is an insect-borne infectious disease caused by the Plasmodium parasite, which spreads to people through Anopheles mosquito bites. It is a complex disease that can spread rapidly and exhibit acute onset. Accordingly, it can easily cause local outbreaks and epidemics and seriously endanger human life and health, as well as social and economic development. In 2018, about 228 million malaria cases occurred worldwide, leading to about 405,000 deaths. The World Health Organization (WHO) observed that the African region accounted for $93.0 \%$ of all cases, followed by Southeast Asia and the eastern Mediterranean region. The global results of malaria elimination efforts are expanding, with 27 countries reporting fewer than 100 local cases and a growing number of countries reporting zero local cases [1,2]. This indicates that malaria elimination is finally within reach. The global burden of malaria is declining through effective control interventions, but monitoring is vital to maintain progress [3]. Since the implementation of the action plan for malaria eradication in China (2010-2020), remarkable achievements have been made in malaria elimination, with more than $95 \%$ of counties in China reporting incidence rates below 1 in 10,000 [4].

Fujian Province has not reported any local cases and is considered to have entered the stage of malaria elimination in 2005 [5]. However, imported malaria cases are often reported in Fujian Province due to frequent commercial exchanges and high mobility in coastal areas [6]. Therefore, it is still necessary to conduct a health economics evaluation of the monitoring measures in Fujian, even though it is in the malaria elimination stage. We reviewed and analyzed the literature on the economics of malaria and found that the differences between the financial and economic costs were negligible; thus, only economic costs are presented here [7-23]. We calculated costs based on health economics theory and the malaria monitoring measures in this stage. We determined the economic analysis framework based on survey data, literature, and expert consultations [7-9]. This approach has allowed us to understand the current input and output characteristics of monitoring measures and analyze their costs and benefits to the province during the malaria elimination stage.

\section{Methods}




\section{Sources of Data}

We collected malaria epidemic data during the final stage of malaria elimination in Fujian Province (2005-2019). The annual malaria report is based on reports of monitoring work and epidemic investigations in various cities. Case investigation data were extracted from the reports of the China Disease Prevention and Control Information System network. Cases were counted according to the time of onset, and duplicate cases were excluded (Table 1). Demographic and economic data were obtained from the Fujian Statistical Yearbook (Table 1).

Table 1

Basic data on the malaria elimination stage in Fujian Province

\begin{tabular}{|llllllllll|}
\hline Year & Population & $\begin{array}{l}\text { Numbers } \\
\text { of cases }\end{array}$ & $\begin{array}{l}\text { Numbers } \\
\text { of } \\
\text { trainees }\end{array}$ & \multicolumn{2}{l}{$\begin{array}{l}\text { Wages of institutions } \\
\text { (yuan \& USD) }\end{array}$} & \multicolumn{2}{l}{$\begin{array}{l}\text { Annual income } \\
\text { (yuan \& USD) }\end{array}$} & \multicolumn{2}{l|}{$\begin{array}{l}\text { Health care costs } \\
\text { (yuan \& USD) }\end{array}$} \\
\hline 2005 & 35570000 & 44 & 46 & 19520.00 & 2810.88 & 8385.50 & 1207.51 & 478.41 & 68.89 \\
\hline 2006 & 35850000 & 49 & 70 & 22232.00 & 3201.41 & 9294.00 & 1338.34 & 513.61 & 73.96 \\
\hline 2007 & 36120000 & 44 & 96 & 26501.00 & 3816.14 & 10486.00 & 1509.98 & 502.41 & 72.35 \\
\hline 2008 & 36390000 & 79 & 66 & 31422.00 & 4524.77 & 12078.50 & 1739.30 & 541.00 & 77.90 \\
\hline 2009 & 36660000 & 63 & 163 & 35557.00 & 5120.21 & 13128.50 & 1890.50 & 592.00 & 85.25 \\
\hline 2010 & 36930000 & 68 & 650 & 39905.00 & 5746.32 & 14604.00 & 2102.98 & 617.00 & 88.85 \\
\hline 2011 & 37200000 & 68 & 1266 & 47060.00 & 6776.64 & 16843.00 & 2425.39 & 773.00 & 111.31 \\
\hline 2012 & 37480000 & 54 & 420 & 53371.00 & 7685.42 & 19011.00 & 2737.58 & 773.00 & 111.31 \\
\hline 2013 & 37740000 & 75 & 344 & 58392.00 & 8408.45 & 19789.50 & 2849.69 & 924.84 & 133.18 \\
\hline 2014 & 38060000 & 86 & 3001 & 63753.00 & 9180.43 & 21686.00 & 3122.78 & 1058.97 & 152.49 \\
\hline 2015 & 38390000 & 97 & 2434 & 73414.00 & 10571.62 & 23534.00 & 3388.90 & 1165.30 & 167.80 \\
\hline 2016 & 38740000 & 108 & 2569 & 80308.00 & 11564.35 & 25506.50 & 3672.94 & 1178.47 & 169.70 \\
\hline 2017 & 39110000 & 142 & 2533 & 90614.00 & 13048.42 & 27668.00 & 3984.19 & 1235.07 & 177.85 \\
\hline 2018 & 39410000 & 107 & 2322 & 101857.00 & 14667.41 & 29971.00 & 4315.82 & 1374.81 & 197.97 \\
\hline 2019 & 39730000 & 108 & 2562 & 113100.00 & 16286.40 & 32274.00 & 4647.46 & 1514.55 & 218.10 \\
\hline Total & 563380000 & 1192 & 18542 & 857006.00 & 123408.87 & 284259.50 & 40933.37 & 13242.44 & 1906.91 \\
\hline
\end{tabular}

\section{Cost Definition and Measuring Method}

Cost was expressed in currency units (RMB 1 yuan= USD 0.144). In the case of this study, no substantial donated items were used and few capital goods were used. As such, the differences between financial and economic costs were negligible and only economic costs are presented here. The basic economic data were obtained from the Fujian Statistical Yearbook. The professionals' wages were calculated according to the wage level of institutions in Fujian Province (Table 2). Based on the domestic and international malaria-related economics literature [5-9], discussions in the research team, consultations with malaria control experts, the Operation Manual of the Malaria Monitoring Program in Fujian Province, and general characteristics of malaria monitoring work, we divided monitoring measures into five categories: 1) case detection and treatment, 2) epidemic monitoring, 3) health education, 4) training and meetings, and 5) supervision and assessment.

1. Case detection and treatment 
Case detection costs included lab professional salaries, blood collection costs, blood smear costs, and microscopic examination costs. The care rate per patient was set at 1 . The direct medical costs included drug treatment, care, and testing costs. The direct non-medical costs were calculated according to the consumption levels of Fujian Province in the same period, including transit fares, accommodation costs, and food expenses. Missed work costs due to hospitalization were converted into a monetary amount by the per capita national income method [9]: Missed work costs $=$ days off work $\times($ per capita national income /306) $\times$ 2.84. One patient missed work on 8 days to be treated for malaria [10].

\section{Epidemic monitoring}

Professional salaries and associated monitoring costs (e.g. materials, transportation etc.) were calculated in units of monitoring sites. The anti-mosquito drug costs for epidemic focus areas were calculated according to the actual amount used and the market price. The professional travel allowances were calculated according to the number of cases.

3. Health education

Since the Fujian Provincial Center for Disease Control and Prevention (FJCDC) carries out health education in Fujian every year, the costs included those of health education and personnel salaries. The health education activities were carried out on World Malaria Day (April 26th). The labor cost was approx. 50 yuan (USD 7.2) per capita.

4. Training and meetings

Trainings for clinicians, monitors, and lab professionals were held every year. The training costs (material, site, lecture, accommodation, transportation, etc.) were calculated by applying the comprehensive quota standard.

The amount of work to be conducted in the form of meetings at the malaria elimination stage is low compared to that of other infectious diseases, so the meeting costs were estimated at $5 \%$ of training costs.

5. Supervision and assessment

The mid-year supervision and year-end assessment costs included materials costs, personnel salaries, and travel allowances. 
Table 2

Estimates of cost-benefit analysis of the malaria elimination

stage in Fujian Province

\begin{tabular}{|lll|}
\hline Indicators & \multicolumn{2}{l|}{ Value (yuan \& USD) } \\
\hline Annual income & 18950.6 & 123408.87 \\
\hline Direct medical cost & 319.35 & 45.99 \\
\hline Direct non-medical cost & 218.94 & 31.53 \\
\hline Missed work cost & $1,407.05$ & 202.62 \\
\hline Training cost (2005-2013) & 130 & 18.72 \\
\hline Training cost (2014-2019) & 400 & 57.60 \\
\hline Blood smear slide & 10 & 1.44 \\
\hline Material cost & 40 & 5.76 \\
\hline Labor cost & 50 & 7.20 \\
\hline Travel allowances (2005-2013) & 80 & 11.52 \\
\hline Travel allowances (2014-2019) & 180 & 25.92 \\
\hline Media monitoring cost & 1000 & 144.00 \\
\hline Training time & $3 \mathrm{~d}$ & $3 \mathrm{~d}$ \\
\hline Missed work days & $8 \mathrm{~d}$ & $8 \mathrm{~d}$ \\
\hline Care rate & 1 & 1 \\
\hline
\end{tabular}

\section{Determining Benefit Indicators}

We reviewed the literature on the economic evaluation of malaria [7-23], held discussions with the research team, consulted the experts on malaria, and then determined the typical benefit indicators. The economic benefits included the direct medical and non-medical benefits of avoiding hospitalization and missed work benefits of avoiding hospitalization. The social benefits included the benefit of improving monitoring ability, health, and health protection awareness.

\section{Cost-benefit Analysis Method}

A cost-benefit analysis was conducted for this study, based on fundamental theories of health economics. The cost (C) of monitoring measures during the malaria elimination stage in Fujian Province was calculated and compared to its benefits (B).

\section{Cost-benefit Analysis of Malaria Monitoring per Capita}

The per capita cost of malaria monitoring is calculated as follows: Cost of malaria monitoring measures in the elimination stage divided by the number of people threatened by malaria. The per capita benefit of malaria monitoring is calculated as follows: Benefit of malaria monitoring measures in the elimination stage divided by the number of people threatened by malaria.

The Benefit-Cost Ratio (BCR) and Net Benefit (NB) are calculated as follows:

Benefit-Cost Ratio $(B C R)=B / C=$ Benefit of malaria monitoring measures in the elimination stage / Cost of malaria monitoring measures in the elimination stage

Net Benefit (NB) = B - C = Benefit of malaria monitoring measures in the elimination stage - Cost of malaria monitoring measures in the elimination stage 
If $\mathrm{BCR}>1$ and NB is positive, the monitoring measures were beneficial to the economy. If $\mathrm{BCR}<1$ and the NB is negative, the monitoring measure cost was higher than the benefit, which means the implementation of those measures was economically burdensome at the malaria elimination stage and the monitoring measures should be adjusted $[12,13]$.

\section{Accounting Assumptions of Cost and Benefit Indicators}

The work of monitoring is less intensive but more targeted in the malaria elimination stage. Thus, we could assume that without the monitoring, large fixed assets would still need to be depreciated and this cost can be excluded from cost estimations. The statutory working hours of professionals can be fully utilized with effective monitoring measures. However, without them, all identified cases will require hospitalization and the assistance of a caregiver (with an assumed care rate of 1), and neither patients nor caregivers can work during hospitalization. We decided it would be practical to calculate the cost of training and health education activities according to the reported project costs. This estimation method did not significantly influence the calculation of social benefits in the cost-benefit analysis. The experts we consulted on the matter confirmed that the indicators that did not meet the inclusion criteria would not have a significant impact on the overall analysis.

\section{Results}

\section{Costs of Malaria Monitoring Measures}

Costs of case detection and treatment: Table 3 shows that the case detection and treatment cost constituted $66.62 \%$ of the total cost $(404,998,744.36$ yuan = USD 58,319,819.19). 
Table 3

Total costs of monitoring measures during the malaria elimination stage in Fujian Province

\begin{tabular}{|c|c|c|c|c|}
\hline Project & Essential factor & Calculation process & $\begin{array}{l}\text { Total cost } \\
\text { (yuan) }\end{array}$ & $\begin{array}{l}\text { Total cost } \\
\text { (USD) }\end{array}$ \\
\hline \multirow[t]{6}{*}{$\begin{array}{l}\text { Case detection and } \\
\text { treatment }\end{array}$} & $\begin{array}{l}\text { Professionals } \\
\text { salaries }\end{array}$ & $\begin{array}{l}135,232 \times 2,210+335,895 \times 170+ \\
385,879 \times 85\end{array}$ & $388,764,585.00$ & $55,982,100.24$ \\
\hline & Blood test costs & $10 \times(1,006,080+191,395)$ & $11,974,750.00$ & $1,724,364.00$ \\
\hline & Direct medical costs & $319.35 \times 1,192$ & $380,665.20$ & $54,815.79$ \\
\hline & $\begin{array}{l}\text { Direct non-medical } \\
\text { costs }\end{array}$ & $218.94 \times 1,192 \times 2$ & $524,336.96$ & $75,504.52$ \\
\hline & Missed work costs & $1,407.05 \times 1,192 \times 2$ & $3,354,407.20$ & $483,034.64$ \\
\hline & Subtotal & & $404,998,744.36$ & $58,319,819.19$ \\
\hline \multirow[t]{5}{*}{ Epidemic monitoring } & Professional salaries & $471,127 \times 74+385,879 \times 64$ & $59,559,654.00$ & $8,576,590.18$ \\
\hline & $\begin{array}{l}\text { Media monitoring } \\
\text { costs }\end{array}$ & $1000 \times 6 \times(37+32)$ & $414,000.00$ & $59,616.00$ \\
\hline & $\begin{array}{l}\text { Anti-mosquito drugs } \\
\text { costs }\end{array}$ & $70,000 \times 5+50,000 \times 6+30,000 \times 4$ & 770,000 & $110,880.00$ \\
\hline & Travel allowances & $80 \times 2 \times 544+180 \times 2 \times 648$ & $320,320.00$ & $46,126.08$ \\
\hline & Subtotal & & $61,063,974.00$ & $8,793,212.26$ \\
\hline \multirow[t]{3}{*}{ Training and meetings } & Training costs & $130 \times 3 \times 3121+400 \times 3 \times 15421$ & $19,722,390.00$ & $2,840,024.16$ \\
\hline & Meeting costs & $19,722,390.00 \times 5 \%$ & $9,861,195.00$ & $1,420,012.08$ \\
\hline & Subtotal & & $29,583,585.00$ & $4,260,036.24$ \\
\hline \multirow[t]{4}{*}{ Health education } & $\begin{array}{l}\text { Health education } \\
\text { costs }\end{array}$ & $20,000 \times 15$ & $300,000.00$ & $43,200.00$ \\
\hline & Professional salaries & $857,006 \times 94$ & $80,558,564.00$ & $11,600,433.22$ \\
\hline & Labor costs & $50 \times 94 \times 15$ & $70,500.00$ & $10,152.00$ \\
\hline & Subtotal & & $80,929,064.00$ & $11,653,785.22$ \\
\hline \multirow{4}{*}{$\begin{array}{l}\text { Supervision } \\
\text { and assessment }\end{array}$} & Material costs & $40 \times 188 \times 15$ & $112,800.00$ & $16,243.20$ \\
\hline & Professional salaries & $857,006 \times 36$ & $30,852,216.00$ & $4,442,719.10$ \\
\hline & Travel allowances & $(720+1080) \times 188$ & $338,400.00$ & $48,729.60$ \\
\hline & Subtotal & & $31,303,416.00$ & $4,507,691.90$ \\
\hline Total cost & & & $607,878,783.36$ & $87,534,544.80$ \\
\hline
\end{tabular}

For the period 2005-2009, blood tests were carried out by two lab professionals in each town. Hence, the data shows that, across the 105 towns, a total of 2,210 lab professionals were required for this period. Subsequently, for the period 2010-2015, blood tests were carried out by two lab professionals in each county. Thus, for 85 counties, there were 170 lab professionals. Finally, for the period 2016-2019, blood tests were carried out by one lab professional in each county. Hence, there were 85 lab professionals in 85 counties.

Accordingly, total lab professional salary costs were $388,764,585.00$ yuan (USD 55,982,100.24). 
The required annual blood test rate was not less than 2/100 in Nanping and Sanming, not less than 5/1,000 in the southern area, and not less than $1 / 1,000$ in other cities. In 2005-2009, the number of patients was 1,006,080. In the period 2010-2019, the required annual blood test rate was not less than 5/10,000 in Fujian and the number of patients was 191,395.

Accordingly, the total blood test cost was $11,974,750.00$ yuan (USD 1,724,364.00).

Overall, 1,192 cases were reported during the malaria elimination stage (2005-2019). The total costs were as follows: direct medical cost was 380,665.20 yuan (USD 54,815.79), direct non-medical cost was 524,336.96 yuan (USD 75,504.52), and missed work cost was $3,354,407.20$ yuan (USD 483,034.64).

Cost of epidemic monitoring: Table 3 shows that the epidemic monitoring cost constituted $10.05 \%(61,063,974.00$ yuan $=$ USD $8,793,212.26)$ of the total cost.

The monitoring work was carried out with two professionals at each site and there were five sites for floating population communities during 2005-2019. There were 15 sites in the southern area and 22 sites in the northwestern area. Hence, with two professionals in each site, there were 74 professionals in 37 sites from 2005 to 2015. Subsequently, for the period 2016-2019, there were 20 sites in Nanping and Sanming, and 7 sites in the other cities, that is, 64 professionals in 32 sites.

The total cost of professionals' salaries was 59,559,654.00 yuan (USD 8,576,590.18). In addition, the Anopheles density is monitored six times per year. Therefore, total media monitoring costs was 414,000.00 yuan (USD 59,616.00);

The anti-mosquito drugs costs were 70,000 yuan (USD 10,080.00) per year between 2005 and 2009), 50,000 yuan (USD 7,200.00) per year from 2010 to 2015, and 30,000 yuan (USD 4,320.00) per year between 2016 and 2019.

Hence, the total anti-mosquito drug cost was 770,000 yuan (USD 110,880.00).

The cases were investigated and verified by two professionals. This incurred a cost for professional travel allowance of $320,320.00$ yuan (USD 46,126.08).

Cost of training and meetings: Table 3 shows that the training and meeting cost was $4.87 \%(29,583,585.00$ yuan $=$ USD $4,260,036.24)$ of total costs. Each training session lasted for approximately three days. In total, 3,121 professionals attended training in the period from 2005-2013 and 15,421 professionals attended between 2014 and 2019.

Hence, the total training cost was 19,722,390.00 yuan (USD 2,840,024.16) and the total meeting cost is estimated at $9,861,195.00$ yuan (USD 1,420,012.08).

Cost of health education: Table 3 shows that the health education cost was 13.31\% $(80,929,064.00$ yuan $=$ USD $\$ 11,653,785.22)$ of total costs. Ninety-four professionals participated in health education every year. The health education activities cost was estimated at 20,000 yuan (USD 2,880.00) every year. Thus, the total health education cost was 300,000.00 yuan (USD $43,200.00$ ). Further, the total professional salary cost for health education was $80,558,564.00$ yuan (USD 11,600,433.22) and the total labor cost was 70,500.00 yuan (USD 10,152.00).

Cost of supervision and assessment: Table 3 shows that the supervision and assessment cost was 5.15\% (31,303,416.00 yuan= USD $\$ 4,507,691.90)$ of the total cost. Thirty-six professionals conducted 188 supervisions and assessments every year. The total material cost was $112,800.00$ yuan (USD 16,243.20), the total professional salary cost was $30,852,216.00$ yuan (USD $4,442,719.10$ ), and the associated total professional travel allowance cost was 338,400.00 yuan (USD 48,729.60).

Table 3 shows that the total cost of monitoring measures during the malaria elimination stage from 2005-2019 was 607,878,783.36 yuan (USD 87,534,544.80). The proportions of monitoring measure costs are shown in Fig. 1.

\section{Benefits Achieved in the Malaria Elimination Stage}

Economic benefits: Without effective monitoring and control measures, the spread of a malaria epidemic would be very fast and seriously damage human health. All cases would need to be treated with anti-malaria drugs in hospitals. The control incidence 
rate in this study, which is $238.25 / 10,000$, is based on the highest incidence of malaria in the years since 1972 [9]. In the malaria elimination stage, the permanent population of Fujian Province was 563.38 million, so the number of potential cases $=$ $238.25 / 10000 \times 563380000=13,422,529$. There were 1,192 cases reported during this stage, so $13,421,337$ cases of malaria may have been avoided as a result of the monitoring measures.

Accordingly, the direct medical benefits of avoiding hospitalization can be calculated as $=319.35 \times 13,421,337=$ $4,286,103,970.95$ yuan (USD 617,198,971.82).

The direct non-medical benefits of avoiding hospitalization can be calculated as $=218.94 \times 13,421,337 \times 2=5,876,935,045.56$ yuan (USD 846,278,646.56).

The benefit which accrues from not missing work due to hospitalization is $=1,407.05 \times 13,421,337 \times 2=37,768,984,451.60$ yuan (USD 5,438,733,761.03).

Social benefits: Social benefits accrue when the professionals (clinicians, monitors, and lab professionals) improve the province's malaria monitoring ability through training. In the malaria elimination stage, the benefit of improving monitoring ability $=250 \times$ $18,542=4,635,500.00$ yuan (USD 667,512.00).

To calculate the value of the benefit of improving health, the health care cost we estimated that residents were willing to spend to avoid malaria, which was 882.83 yuan (USD 127.13), needs to be considered. Thus, the value of the benefit of improved health can be calculated as $882.83 \times 13,421,337=11,848,758,943.70$ yuan (USD 1,706,221,287.89).

It was assumed that, as a result of the health education activities, all residents would acquire prevention knowledge and avoid malaria infection. Combined with the survey results [10], it was estimated that the social benefit of this education was 100 yuan (USD 14.40) per capita. Accordingly, the total benefit of improving health protection awareness was calculated as $100 \times$ $563,380,000=56,338,000,000.00$ yuan (USD 811,267,200.00).

In sum, the total benefit achieved in the malaria elimination stage was $116,123,417,911.81$ yuan (USD $16,721,772,179.30$ ) (Fig. 2). As shown in Table 4, the economic benefit was $22.61 \%(47,932,023,468.11$ yuan $=$ USD 6,902,211,379.41) of the total amount. The social benefit constituted $77.39 \%(164,055,441,379.92$ yuan $=$ USD $23,623,983,558.71)$ of the total.

Table 4

Total benefits of the malaria elimination stage in Fujian Province

\begin{tabular}{|c|c|c|c|c|}
\hline Project & Essential factor & Benefit (yuan) & Benefit (USD) & $\begin{array}{l}\text { Proportion } \\
\text { (\%) }\end{array}$ \\
\hline \multirow[t]{4}{*}{$\begin{array}{l}\text { Economic } \\
\text { benefit }\end{array}$} & $\begin{array}{l}\text { Direct medical benefit of avoiding } \\
\text { hospitalization }\end{array}$ & $4,286,103,970.95$ & $617,198,971.82$ & 3.69 \\
\hline & $\begin{array}{l}\text { Direct non-medical benefit of avoiding } \\
\text { hospitalization }\end{array}$ & $5,876,935,045.56$ & $846,278,646.56$ & 5.06 \\
\hline & $\begin{array}{l}\text { Missed work benefit of avoiding } \\
\text { hospitalization }\end{array}$ & $37,768,984,451.60$ & $5,438,733,761.03$ & 32.52 \\
\hline & Subtotal & $47,932,023,468.11$ & $6,902,211,379.41$ & 22.61 \\
\hline \multirow[t]{4}{*}{ Social benefit } & Benefit of improving monitoring ability & $4,635,500.00$ & $667,512.00$ & 0.01 \\
\hline & Benefit of improving health & $11,848,758,943.70$ & $1,706,221,287.89$ & 10.20 \\
\hline & $\begin{array}{l}\text { Benefit of improving health protection } \\
\text { awareness }\end{array}$ & $56,338,000,000.00$ & $811,267,200.00$ & 48.52 \\
\hline & Subtotal & $164,055,441,379.92$ & $23,623,983,558.71$ & 77.39 \\
\hline Total benefit & & $1,161,23,417,911.81$ & $16,721,772,179.30$ & 100.00 \\
\hline
\end{tabular}




\section{Cost-benefit Analysis of Malaria Monitoring}

In the malaria elimination stage, the permanent population of Fujian Province was 563.38 million and the total cost of monitoring measures was $607,878,783.36$ yuan (USD 87,534,544.80). This means that the cost of malaria monitoring per resident was 1.08 yuan (USD 0.16). The total benefit achieved in the malaria elimination stage was 116,123,417,911.81 yuan (USD 16,721,772,179.30), which means the benefit of malaria monitoring for each resident was 206.12 yuan (USD 29.68). Hence, the results show that the malaria monitoring measure cost per capita was less than the benefit per capita in Fujian Province. Hence, the effect of the malaria monitoring work was very beneficial. Specifically, BCR = B / C = 116,123,417,911.81 / $607,878,783.36=191.03$ and $\mathrm{NB}=\mathrm{B}-\mathrm{C}=116,123,417,911.81-607,878,783.36=115,515,539,128.45$ yuan (USD $16,634,237,634.50)$.

\section{Discussion}

Cost-benefit analysis is one of the most important tools in health economics research, and can be used to effectively evaluate the impacts of health and epidemic prevention efforts [14]. This study identified the characteristics of malaria elimination efforts in Fujian Province and comprehensively analyzed the inputs and outputs to monitoring in the malaria elimination stage.

Literature has shown that implementing more effective malaria monitoring and control measures can produce economic benefits [15-21]. At present, malaria monitoring measures in Fujian Province have been incorporated into overall public health efforts. The malaria monitoring measures for imported cases have been strengthened and the diagnostic knowledge of clinicians and the ability of monitoring personnel and lab personnel, enhanced. Health education activities have been carried out through multiple channels, and the achievements in malaria control have been consolidated. Overall, the monitoring work has achieved enormous economic and social benefits in the malaria elimination stage.

The study estimated the cost based on the monitoring measures, although some influencing factors could not be taken into account. However, we assume that this did not significantly impact results. At present, Fujian Province is at the stage of malaria elimination and malaria-related efforts are gradually being reduced. If we had used traditional cost accounting, the accuracy of the results may have been adversely affected. Therefore, in our framework, we determined the cost structure according to the malaria monitoring measures. This approach was intended to more accurately reflect the direct cost of the monitoring measures, similar to the methods in other relevant studies $[7,14]$.

The results showed that the total cost of monitoring measures was $607,878,783.36$ yuan (USD 87,534,544.80) in the malaria elimination stage. Although the cost of monitoring measures was large, it was still within a reasonable range for infectious disease control and prevention. The case detection and treatment costs accounted for $66.62 \%(404,998,744.36$ yuan $=$ USD $58,319,819.19$ ) of total cost. Health education costs accounted for $13.31 \%$, epidemic monitoring costs were $10.05 \%$, supervision and assessment costs were $5.15 \%$, and training and meetings were the smallest cost factor at $4.87 \%$ of the total. As the population is generally susceptible to malaria, it was necessary to carry out blood tests on febrile patients, which explains why the case detection costs made the highest contribution to total cost. At present, the majority of imported cases in the province are falciparum malaria cases. The density of the Anopheles sinensis and the risk of re-transmission of falciparum malaria are very low. Therefore, the focus of the malaria elimination stage is discovering and treating the sources of infection and reducing mortality. This focus on infectious sources is different from malaria-endemic areas in Africa, which mainly emphasizes blocking infectious sources, controlling transmission routes, and protecting susceptible populations $[19,22,23]$. The study concludes that, for Fujian Province, monitoring personnel should adopt more targeted measures, focusing on the detection of imported cases in the malaria elimination stage. A malaria special working group should be set up to take more targeted monitoring measures and thereby, reduce the proportion of personnel salaries in the total cost equation. This will reduce the overall monitoring cost and enable costs to be accounted for more accurately. In this stage, the focus of training should be shifted to clinicians to improve their diagnostic ability.

The cost-benefit analysis of the malaria elimination stage showed that the cost of malaria monitoring for each resident was 1.08 yuan (USD 0.16) per capita and the benefit for each resident was 206.12 yuan (USD 29.68). This shows that the malaria monitoring cost per capita was relatively low, and the effectiveness was positive. The total benefit was 116,123,417,911.81 yuan 
(USD 16,721,772,179.30), the NB was 115,515,539,128.45 yuan (USD 16,634,237,634.50), and the BCR was 191.03. Thus, the monitoring measures are economically favorable in this stage. The incidence of imported cases was managed cost effectively. The monitoring measures are targeted and have high monitoring sensitivity.

The study results showed that health education costs accounted for $13.31 \%(80,929,064.00$ yuan $=$ USD 11,653,785.22), while the benefits of improving prevention awareness accounted for $48.52 \%(56,338,000,000.00$ yuan $=$ USD $811,267,200.00)$. This indicates that the BCR for health education was relatively high (696.14). Therefore, investments in health education could be increased. The health education workers should enhance the level of education on malaria prevention for the personnel who go to high-prevalence areas.

In the malaria elimination stage, different monitoring measures were applied according to different risk levels, thus strengthening the prevention and control for the imported cases. These measures conformed to the global malaria strategy (World Health Assembly 2015) and were also similar to those observed in past studies [16, 20,24].

Given time and research capacity constraints, some potentially influential factors (such as the policy environment) were not considered at this stage. Further, some data were estimated based on interview results, which may have interfered with the accuracy of the analysis results.

\section{Conclusions}

The monitoring measures conducted in the malaria elimination stage are a highly cost-effective intervention for reducing the negative impact of malaria in Fujian Province. The cost-benefit analysis of the malaria elimination stage shows that the NB of monitoring measures, which is $115,515,539,128.45$ yuan (USD 16,634,237,634.50), as well as the BCR, which is 191.03. The monitoring cost for each resident is 1.08 yuan (USD 0.16) and the benefit is 206.12 yuan (USD 29.68). These values show that the per capita malaria monitoring cost is relatively low, and the effectiveness is positive. Although some limitations are present, this study remains significant. The cost-benefit analysis approach allows us to understand the current input and output characteristics of malaria monitoring in Fujian Province and analyze the benefits of monitoring measures in the malaria elimination stage. The study not only provides reference for future malaria elimination research but also a scientific basis for more rational formulations of malaria monitoring programs in Fujian Province. Future studies may use modifications to this approach to obtain more precise results, which will serve as an even more comprehensive reference for the malaria monitoring work.

\section{Abbreviations}

BCR: benefit-cost ratio; NB: net benefit; WHO: World Health Organization;

\section{Declarations}

\section{Ethics approval and consent to participate}

This study is a health economics study on malaria monitoring measures, so it was only the aggregate total not individual subjects therefore "Not applicate".

\section{Consent for publication}

Not applicable

\section{Availability of data and materials}

The datasets used and/or analyzed during the current study are available from the corresponding author on reasonable request.

\section{Competing interests}


The authors declare that they have no competing interests.

\section{Funding}

This study was a part of a research program on the malaria elimination strategy and post-elimination monitoring system in Fujian and was supported by the Fujian Science and Technology Program Guidance Project (No. 2016Y0009).

\section{Authors' Contributions}

SYZ and CYH conceived of and designed the study; ZYC, HGX, and ROY contributed to the data collection; CYH drafted the manuscript; and SYZ and ZYC revised the manuscript. All authors read and approved the final manuscript.

\section{Acknowledgements}

We would like to thank Editage (www.editage.cn) for English language editing.

\section{Publisher's Note}

Springer Nature remains neutral with regard to jurisdictional claims in published maps and institutional affiliations.

\section{References}

1. Global Malaria Programme: World Malaria Report 2019. In. Geneva: WHO; 2019: 232.

2. Howes RE, Battle KE, Mendis KN, Smith DL, Cibulskis RE, Baird JK, Hay SI: Global Epidemiology of Plasmodium vivax. Am J Trop Med Hyg 2016; 95:15-34.

3. Kigozi SP, Giorgi E, Mpimbaza A, Kigozi RN, Bousema T, Arinaitwe E, Nankabirwa JI, Sebuguzi CM, Kamya MR, Staedke SG et al: Practical Implications of a Relationship between Health Management Information System and Community Cohort-Based Malaria Incidence Rates. Am J Trop Med Hyg 2020.

4. Tang LH, Gao Q: Proposal of China's Action Plan to Eliminate Malaria. Shanghai: Shanghai Science and Technology Publishers; 2013.

5. Tang LH: Diagnosis, treatment and management of imported malaria. Shanghai: Shanghai Science and Technology Publishing House; 2010.

6. Ou Yang R, Chen YL, Xie HG, Lin YY, Xiao LZ, Zhang SY: Prevalent trend and control strategy of importedmalaria in Fujian Province, China, 2011-2017. C J Zoonosis 2019; 35(4):359-62.

7. Silumbe K, Yukich JO, Hamainza B, Bennett A, Earle D, Kamuliwo M, Steketee RW, Eisele TP, Miller JM: Costs and costeffectiveness of a large-scale mass testing and treatment intervention for malaria in Southern Province, Zambia. Malar $\mathrm{J}$ $2015 ; 14: 211$.

8. Fang HQ: The current situation of malaria surveillance ability and its cost-effectiveness analysis in grass-root areas of China. Wuhan: Huazhong University of Science and Technology; 2016.

9. Huang CY, Yang FZ, Ou Yang R, Chen ZY, Zhang SY: Cost-effectiveness analysis of surveillance measures at different stages of malaria elimination in Fujian Province. Chinese Journal of Zoonosis 2017; 33(10):933-7.

10. Liu XZ, Chen YL: Socioeconomic Research on Malaria Control. Haikou: Nan Hai Publishing Co.; 1997.

11. Akhavan D, Musgrove P, Abrantes A, d'A Gusmão R: Cost-effective malaria control in Brazil. Cost-effectiveness of a Malaria Control Program in the Amazon Basin of Brazil, 1988-1996. Soc Sci Med 1999; 49(10):1385-99.

12. Zhuang RS, Wang SY: How to evaluate the economic burden of disease? Chin J Prev Med 2001; 2(4):245-7.

13. Sudathip P, Kongkasuriyachai D, Stelmach R, Bisanzio D, Sine J, Sawang S, Kitchakarn S, Sintasath D, Reithinger R: The Investment Case for Malaria Elimination in Thailand: A Cost-Benefit Analysis. Am J Trop Med Hyg 2019; 100(6):1445-53.

14. Chang AY, Horton S, Jamison DT: Benefit-Cost Analysis in Disease Control Priorities, Third Edition. Washington (DC): The International Bank for Reconstruction and Development /The World Bank; 2017. 
15. Ezennia IJ, Nduka SO, Ekwunife Ol: Cost benefit analysis of malaria rapid diagnostic test: the perspective of Nigerian community pharmacists. Malar J 2017; 16(1):7.

16. Kim HS, Kang G, Lee S, Yoon CG, Kim M: Cost-Benefit Analysis of Malaria Chemoprophylaxis and Early Diagnosis for Korean Soldiers in Malaria Risk Regions. J Korean Med Sci 2018; 33(10):e59.

17. Devine A, Parmiter M, Chu CS, Bancone G, Nosten F, Price RN, Lubell Y, Yeung S: Using G6PD tests to enable the safe treatment of Plasmodium vivax infections with primaquine on the Thailand-Myanmar border: A cost-effectiveness analysis. PLoS Negl Trop Dis 2017; 11(5):e0005602.

18. Chaccour CJ, Alonso S, Zulliger R, Wagman J, Saifodine A, Candrinho B, Macete E, Brew J, Fornadel C, Kassim H et al: Combination of indoor residual spraying with long-lasting insecticide-treated nets for malaria control in Zambezia, Mozambique: a cluster randomised trial and cost-effectiveness study protocol. BMJ Glob Health 2018; 3(1):e000610.

19. Hailu A, Lindtjørn B, Deressa W, Gari T, Loha E, Robberstad B: Cost-effectiveness of a combined intervention of long lasting insecticidal nets and indoor residual spraying compared with each intervention alone for malaria prevention in Ethiopia. Cost Eff Resour Alloc 2018; 16:61.

20. Sauboin C, Van Bellinghen LA, Van De Velde N, Van Vlaenderen I: Economic Impact of Introducing the RTS,S Malaria Vaccine: Cost-Effectiveness and Budget Impact Analysis in 41 Countries. MDM Policy Pract 2019; 4(2):2381468319873324.

21. Assebe LF, Kwete XJ, Wang D, Liu L, Norheim OF, Jbaily A, Verguet S, Johansson KA, Tolla MT: Health gains and financial risk protection afforded by public financing of selected malaria interventions in Ethiopia: an extended cost-effectiveness analysis. Malar J 2020; 19(1):41.

22. Zelman BW, Baral R, Zarlinda I, Coutrier FN, Sanders KC, Cotter C, Herdiana H, Greenhouse B, Shretta R, Gosling RD et al: Costs and cost-effectiveness of malaria reactive case detection using loop-mediated isothermal amplification compared to microscopy in the low transmission setting of Aceh Province, Indonesia. Malar J 2018; 17(1):220.

23. Winskill P, Walker PG, Griffin JT, Ghani AC: Modelling the cost-effectiveness of introducing the RTS,S malaria vaccine relative to scaling up other malaria interventions in sub-Saharan Africa. BMJ Glob Health 2017; 2(1):e000090.

24. Winskill P, Walker P, Cibulskis R, Ghani A: Prioritizing the scale-up of interventions for malaria control and elimination. Malar J 2019; 18(1):122.

\section{Figures}

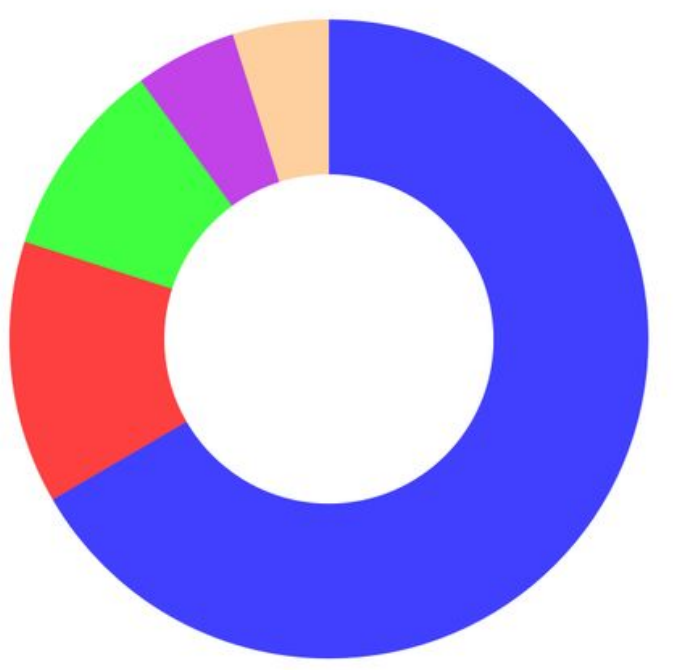

\begin{tabular}{lr} 
- Case detection and treatment & $71.53 \%$ \\
\hline Health education & $12.28 \%$ \\
\hline Epidemic monitoring & $8.84 \%$ \\
Supervision and assessment & $4.48 \%$ \\
\hline Training and meetings & $2.87 \%$
\end{tabular}

\section{Figure 1}

The proportion of the cost of individual monitoring measures to the total cost during the malaria elimination stage in Fujian Province 


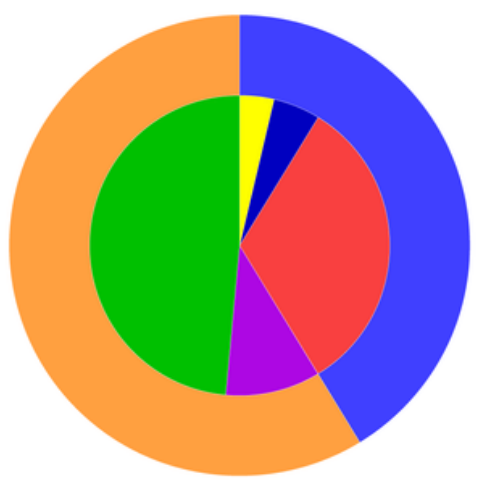

Economic benefit

Direct medical benefit of avoiding hospitalization

Direct non-medical benefit of avoiding hospitalization

Missed work benefit of avoiding hospitalization

Social benefit

Benefit of improving monitoring ability

Benefit of improving health

Benefit of improving protection awareness
$41.27 \%$

$3.69 \%$

$5.06 \%$

$32.52 \%$

$48.52 \%$

$0.01 \%$

$10.2 \%$

$48.52 \%$

\section{Figure 2}

The proportion of economic and social benefits in the total benefits from the malaria elimination stage in Fujian Province 